\title{
Voice User Interface for the Neurodiversant
}

\author{
Dr Bheemaiah, Anil Kumar \\ Graduate Student UMN Twin Cities. \\ psychEDU@yopmail.com
}

\section{Abstract}

Technology for the neurodivergent has embraced VUI in the form of several off the shelf cloud based technologies, replacing older speech generation technology, in this paper we use Amazon VUI as an example of accommodation engineering and digital literacy as we review the use of VUI technologies and a move away from $A B A$ Therapy by the neurodivergent community.

Keywords: VUI, Alexa, Echo, Neurodiversant, Neurotypical, Digital Literacy, Digital Divide.

Alexa For the Neurodiversant. (Admin, 2016; Amazon Echo for Disabilities | 8 Alexa Uses for Disabled People | Autism, 2020, Autism Help, n.d., How Amazon's Alexa Is Helping My Son With a Disability, 2017, How Amazon's Alexa Is Helping Our Child With Autism, ADHD and Sensory Processing Disorder - Sensory Mom Secrets, 2019, [No Title], n.d., Top 10 Autism Skills on Amazon Alexa, 2018, Using Amazon Echo To Develop Speech Skills in Your Autism Classroom or Home School, n.d., Website, n.d.; Darrow, 2017a, 2017b; Eileen, 2018) delineate a range of informal, web-based articles on Alexa skills and the usability by the autistic community, the predominant application being independent living and daily routine skills with many game-based skills for social skills and also for daily routines. In contrast to Amazon Pollexy, which uses a goal-directed approach with an AWS Lex supportive voice, the majority of popular Alexa skills use open-ended game playing for daily routines and adding creativity to mundane habits.

(Admin, 2016) illustrates, the practicality of digital assistants in the case of a neurodiverse child, the son of the author, in language development, by the simple recognition system of Alexa, in recognizing well-formed language, with the reinforcements of controls, in controlling a smart home, gaining practical information and using Alexa for shopping, young autistic children gain valuable life skills, across the digital divide.

(Eileen, 2018), a parent of an autistic child writes about the use of Amazon Alexa blueprints in the creation of unlimited skills to help her child with her daily routines, skills to bring the family together, communicate within the home, and an unlimited number of applications, with the sky, the limit.

(Amazon Echo for Disabilities | 8 Alexa Uses for Disabled People | Autism, 2020) discuss several uses for Alexa, with his children, both neurodivergent, timers are proven invaluable and so is the need for slow and clear pronunciation by the children, help with executive skill planning is a boon, and help with IEP is available through skills the author of this article is writing and in the process of enhancing. (How Amazon's Alexa Is Helping My Son With a Disability, 2017)The author talks about learning and peers networking with Alexa, the gradual learning by asking 
repetitive skills, and an increase in learning and question forming, made possible only by Alexa, across the digital divide.

(Bendfeldt-Diaz, 2018), discuss the miracles, Alexa has brought in their child's life, in many ways ranging from, improving sibling relationships, by using kids court a skill with a fictional judge Lexy who resolves sibling disputes, improves social skills, as children who are neurodivergent find Alexa more accessible than a peer group, self-confidence in game-playing and better control of digital life.

(Using Amazon Echo To Develop Speech Skills in Your Autism Classroom or Home School, n.d.) discuss the use of Alexa in the classroom or in homeschooling for language skill development using facts, fun information, and in video modeling. (Autism Help, n.d.) is an Alexa skill to help with verbal, skills, learning and functional and social skills with kudos as feedback. (Top 10 Autism Skills on Amazon Alexa, 2018) cites these top ten skills:

\section{Autism Alexa Skills Links}

\begin{tabular}{|l|}
\hline \#1) Autism Cure in Thirty Days \\
\hline \#2) Autism Success Stories \\
\#3) Autism Truths What is Autism How to Thrive with it \\
\hline \#4) Autism Cure Webinar \\
\hline \#5) Autism Cure Top Eight Scientific Discoveries \\
\hline \#6) Autism Facts \\
\hline
\end{tabular}

\begin{tabular}{|l|}
\hline$\# 7$ ) Autism Teeth Grinding Permanent Cure \\
\hline \#8 ) Autism Solutions \\
\hline \#9) Autism Cure \\
\#10) Autism News \\
\end{tabular}

([No Title], n.d.) is beyond the digital divide with education on the use of digital technology for the neurodivergent, elopement technology, mixed reality glasses, tablets, and Alexa are introduced with a host of other technologies for accommodations.

\section{VUI and the Digital Divide.}

Voice interfaces may replace the need for visual interfaces in the use of computers as cost effective cloud based thin clients become popular, instanced by the success of Google Home , Samsung Bixby and Amazon Echo. VUI skills replace application programs, in the use of cloud functions and resources, with an interface based on natural language processing, which is a lot more natural compared to the use of programming languages. Digital Literacy is thus possible though natural language.

VUI like Amazon Alexa is digital literacy as evidenced in many of the references delineated in the previous paragraph, an addition to the classroom and homeschooling, a range of skills are available today to help ease the transitioning required, providing pervasive A.I towards accommodations, functional, social and learning, communication skills. Blueprints a template system, has made skill writing accessible to the neurodivergent. 
Discussion and Future Work.

Alexa is thus presented as an invaluable resource, as a voice user interface, evidenced by several articles on practical use cases, with several blueprints based skills and commercial skills for the neurodivergent. With strong evidence on the efficacy of Alexa in a neurodivergent digital life, in self-advocacy and self-determination and in digital literacy and a transitioning to independent living, even IEP help is provided by Alexa.

In the future, as more skills for the neurodivergent are published, future papers will include more information and evidence on the efficacy of Alexa in functional, social, and communication skills.

\section{Reference.}

Admin, A. H. O. (2016, March 13). Amazon

Echo - A virtual assistant for your home. http://autismhelponline.com/blog/2016/03/12/ amazon-echo-more-than-just-another-virtualassistant/

Amazon Echo for Disabilities | 8 Alexa Uses for Disabled People | Autism. (2020). https://adayinourshoes.com/alexa-amazon/

Autism Help. (n.d.). Retrieved December 12, 2020 , from https://www.amazon.com/Daphne-Mallory-Au tism-Help/dp/B078RG49WP

Bendfeldt-Diaz, P. (2018, May 23). 8 Life-Changing Ways Amazon's Echo Dot Kids Helps Children With Special Needs. https://growingupbilingual.com/8-ways-amaz ons-echo-kids-edition-is-a-great-tool-for-kidswith-special-needs/

Darrow, B. (2017a, April 17). Amazon Alexa Can Help People With Autism Do More On Their Own. Fortune. https://fortune.com/2017/04/17/amazon-alex a-autism/

Darrow, B. (2017b, April 17). Amazon Alexa Can Help People With Autism Do More On Their Own. Yahoo Finance. http://finance.yahoo.com/news/amazon-alex a-help-people-autism-221043353.html

Eileen. (2018, May 3). How we use our Amazon Echo to connect as a family. https://theautismcafe.com/alexa-connects-ou r-family/

How Amazon's Alexa Is Helping My Son With a Disability. (2017, November 9). https://themighty.com/2017/11/how-amazons -alexa-is-helping-my-son-with-a-disability/

How Amazon's Alexa is Helping Our Child With Autism, ADHD and Sensory Processing

Disorder - Sensory Mom Secrets. (2019, January 15).

https://www.sensorymomsecrets.com/alexaautism-adhd-sensory/

[No title]. (n.d.). Retrieved December 12, 2020, from 
https://www.monarchcenterforautism.org/web inars/viewdocument/52

Top 10 Autism Skills on Amazon Alexa. (2018, July 1$)$.

https://authenticautismsolutions.com/top-10autism-skills-amazon-alexa/

Using Amazon Echo To Develop Speech Skills in Your Autism Classroom or Home School. (n.d.). Retrieved December 12, 2020, from https://autismeducators.com/using-amazon-e cho-to-develop-speech-skills-in-your-autismclassroom-or-home-school

Website. (n.d.). Retrieved December 12, 2020, from

https://www.curriculumforautism.com/blog/usi ng-amazons-alexa-to-develop-speech-skills-i n-your-autism-classroom-or-home-school 